\title{
Pesticides Recovery and Detection from Agricultural Soil Leachates Using Gas Chromatography Masses with Electron Capture Detector
}

\author{
Lluvia Paola Medina-Armenta1, Gustavo Cruz-Jiménez², Margarita Teutli-León³, Luis A. García \\ de la Rosa ${ }^{4}$, Rossy Feria-Reyes ${ }^{1}$
}

${ }^{1}$ Chemistry Department, Guanajuato University, Guanajuato, Mexico

${ }^{2}$ Pharmacia Department, Guanajuato University, Guanajuato, Mexico

${ }^{3}$ Engineering Department, Distinguished Autonomous University of Puebla, Puebla, Mexico

${ }^{4}$ UPIG, Chemistry Department, National Polytechnic Institute, Guanajuato, Mexico

Email: rossyfr@gmail.com

How to cite this paper: Medina-Armenta, L.P., Cruz-Jiménez, G., Teutli-León, M., de la Rosa, L.A.G. and Feria-Reyes, R. (2017) Pesticides Recovery and Detection from Agricultural Soil Leachates Using Gas Chromatography Masses with Electron Capture Detector. American Journal of Analytical Chemistry, 8, 605-616. https://doi.org/10.4236/ajac.2017.810043

Received: August 18, 2017

Accepted: October 21, 2017

Published: October 24, 2017

Copyright $\odot 2017$ by authors and Scientific Research Publishing Inc. This work is licensed under the Creative Commons Attribution International License (CC BY 4.0).

http://creativecommons.org/licenses/by/4.0/

\begin{abstract}
In this study, it is reported an analytical approach to recover organochlorine pesticides from a clay soil. Soil was physical and chemically characterized. Also pesticides extraction was carried out using packed columns and various aqueous media $\left(\mathrm{H}_{2} \mathrm{O}\right.$-milliQ, $\mathrm{NaOH}, \mathrm{HCl}$, SDS, Triton $\mathrm{X}-114$, Humic acids and Acetonitrile). The leachate samples were analyzed on an Agilent Technologies $6890 \mathrm{~N}$ Gas Chromatograph with electron capture in a\# AB002 Column $30.0 \mathrm{~m} \times 250 \mu \mathrm{m} \times 0.25 \mu \mathrm{m}$ calibrated, 25 psi pressure, flow $2.9 \mathrm{ml} / \mathrm{min}$, temperature $25^{\circ} \mathrm{C}$, ultra-high purity Helium as the entrainment gas and an elution time of $50 \mathrm{~min}$. The results show that the highest extraction percentage of pollutants in the soil washing was obtained with acetonitrile recovering: $p, p^{\prime}$-DDT (91.0\%); $p, p^{\prime}$-DDE (92.0\%); $p, p^{\prime}$-DDD (96.0\%); aldrin (98.6\%); dieldrin (98.0\%). With Triton X-114, the extractions recovery was: $p$, $p^{\prime}$-DDT (63.0\%); $p, p^{\prime}$-DDE (64.0\%); $p, p^{\prime}$-DDD (65.0\%); aldrin (67.0\%); dieldrin $(72.0 \%)$. This study illustrates the potential Applicability of SPME for routine analysis of organochlorine pesticides in soils.
\end{abstract}

\section{Keywords}

Leaching of Organochlorine Compounds, Surfactants, Desorption of Pesticides, Packed Columns, Soil, Gas Chromatography-ECD

\section{Introduction}

In Mexico, approximately 4.55 tons of pesticides (fungicides, herbicides and in- 
secticides) were spread over 1000 hectares between 2009 and 2010 [1]. In 2013 pesticide use amounted to 37,455 tons of insecticides, 31,195 tons of herbicides and 42,223 tons of fungicides [2]. In Mexico, approximately 4.55 tons of pesticides (fungicides, herbicides and insecticides) were spread over 1000 hectares between 2009 and 2010 [1]. The characteristics of pesticides, such as high lipophilicity, bioaccumulation, long half-life and potential of long range transport, have increased the chances of contaminating the air, water and soil, even after many years of application [3]. They are persistent, estrogenic, carcinogenic [4], and able to bio-accumulate and bio-magnify through the biological chain [5]. Unfortunately, the utilization of these pesticides inevitably generates a large amount of polluted soil sites due to the stability of organochlorine compounds. Currently, the problem of highly pesticides polluted soil has become one of the most worrying issues in environmental protection [6]. Remediation of soil and sediment material containing organochlorine compounds can be problematic because of slow kinetics. It has been shown that equilibrium of organochlorine compounds between sorbent particles and water can last on the order of years [7]. This suggests that sorption of pesticides occurs with only a limited degree of reversibility depending upon both the chemical itself (e.g. its structure and solubility) and the soil properties involved (e.g. texture and soil physico-chemical parameters) [8]. Thus, soil can be regarded as an entity that is initially able to bind pesticides by functioning as a quasi-permanent sink, but then also may release those products back into the soil solution [9]. Ex situ soil washing in combination with environmentally friendly additives as cosolvents [10], surfactants [11] [12], humic acid [6], may be a promising technology for achieving that goal [13]. It is recommended to include a solvent aided extraction and pre-concentration stage, so the increase on selectivity is favored. Laboratory studies have indicated that hydrophobic organic compounds can display adsorption/desorption non-singularity, a phenomenon also known as hysteresis [14]. While hysteresis is a pervasive and widely studied phenomenon, and adsorption/desorption hysteresis has been well-known for water silica gel systems for over a century, HOC-related adsorption hysteresis is poorly understood [15]. Pesticide leaching and desorption in soils has been assessed with different extractants in aqueous media as surfactants Brij 35, Tween 80, and SDS; or with organic solvents like acetone, triethylamine, and squalane [16]. A new approach using surfactants as Triton X-114, SDS and CTAB aided soil washing process to improve the performance of adsorption/desorption of atrazine in soil clays resulting a $95.0 \%$ of atrazine desorption with nonionic surfactant [17].

To developing a simple, rapid and sensitive method on organochlorine pesticides determination is of great importance. Chromatographic techniques are usually used to determine pesticides [18]. Before determination, many preliminary steps, such as sampling, extraction, and clean-up for interference removal, need to be done. Typically, the sample pretreatment methods of organochlorine pesticides include liquid-liquid extraction [19], solid-liquid extraction [20]. Solid-phase microextraction (SPME) is a solvent-free extraction technique that 
represents an easily automated alternative to conventional extraction methods [21]. SPME can avoid the toxic solvents or plugging of cartridges [22], so it is obviously more beneficial than the traditional sample pre-treatment methods [23] [24].

In this study, it reports the results of evaluation for the extraction and mobility of organochlorine compounds in soils from Salamanca, Guanajuato State, Mexico. Near the chemical fertilizer manufacture, there stores at least 70,000 tons of industrial waste in its facilities, including fertilizers and pesticides, causing pollution by suspended particles that are scattered by wind gusts, and the leachate of products to the surrounding agricultural fields reaching high concentrations of organochlorine and organophosphorus compounds such as $p$, $p^{\prime}$-DDT, $p, p^{\prime}$-DDE, $p, p^{\prime}$-DDD, Aldrin and Dieldrin. For this study, different aqueous media such as surfactants, electrolytic solutions and humic acids were used in packed column systems to determine the mobility of pollutants in soils and the relationships between the physicochemical properties of the soils and the sorption and lixiviation.

\section{Materials and Method}

\subsection{Materials}

Soil samples were collected from agricultural soils nearby to a chemical plant; samples were obtained at $50.0 \mathrm{~cm}$ depth. Soil samples were dried at room temperature and were sifted with a mesh size of $2.0 \mathrm{~mm}$ (NOM-021-SEMARNAT2000).

\subsection{Reagents}

All reagents used in the study were analytical grade. The humic acid was reactive grade from Sigma Aldrich (98\%), the humic acid solution was prepared to provide $5.0 \mathrm{mg} \cdot \mathrm{L}^{-1}$ in $1 \times 10^{-3} \mathrm{M}$ of $\mathrm{NaOH}$ solution. Also acetonitrile HPLC grade (Caledon 99\%), the washing solutions and extractants were: anionic surfactant sodium dodecyl sulfate (SDS) (96\% Sigma Aldrich), nonionic surfactant, Triton X-114 (Sigma Aldrich) and Hexane grade HPLC (Sigma Aldrich To 97\%).

The Organochlorines compound standard for the optimization method were aldrin (1,2,3,4,10,10-Hexachloro-1,4,4a,5,8,8a-hexahydro-1, 4:5,8-dimethanonaphthalene), dieldrin((1aR,2R,2aS,3S,6R,6aR,7S,7aS)-3,4,5,6,9, 9-hexachloro-1a,2,2a,3,6,6a,7,7a-octahydro-2,7:3,6-dimethanonaphtho[2,3-b]oxi rene), and DDT (1,1,1-trichloro-2,2-di(4-chlorophenyl)ethane),

$\operatorname{DDD}$ (2,4-Dichlorodiphenyl)di-chloroethane,1-(2-Chlorophenyl)-1-(4-chloroph enyl)-2,2-dichloroethane,o,p-DDD, and DDE

2-(2-Chlorophenyl)-2-(4-chlorophenyl)-1,1-dichloroethene, o,p-DDE. All these compounds were obtained from Sigma-Aldrich.

\subsection{Physical and Chemical Analysis of Soil}

Soil analysis testing was done in triplicate, for the following parameters accord- 
ing to the techniques cited between parenthesis: Cation Exchange Capacity (C.E.C., ASTM-D7503-10), Organic Matter (O.M. ASTM-D 2974), Textural Analysis (ASTM-152H), Particle Density (ASTM-D854-10), Bulk Density (ASTM-D2854-09), Soil Porosity (ASTM-D4404-10), pH (ASTM-D4972-89), Field Capacity and Percentage of Hygroscopic Water (ASTM-D4959-89).

\subsection{Analysis of Contaminated Soil by X-Ray Diffraction (XRD)}

The X-ray diffraction study allows to identify the mineralogical phases soil, such as clay fractions; for this step, it was used a powder difractometermRC SIEMENS D-500, with X-Ray tube, copper cathode at a wavelength $\mathrm{CuK}$ of 1.5418, plus nickel filter with $30 \mathrm{KV}$ and $20 \mathrm{~mA}$. It must be mentioned that measurements were done at $30^{\circ}$ value respect to the $2 \theta$ angle.

\subsection{Thermogravimetric Analysis (TGA) of Contaminated Soil}

This analysis was carried out on $10 \mathrm{mg}$ soil samples, previously sieved and homogenized, using a heating program of the Simultaneous TGA/DSC equipment: TA Instrument and model SDT-Q600, using temperature ranges from $0^{\circ} \mathrm{C}$ to $1200^{\circ} \mathrm{C}$, with a heating rate of 5 degrees/min and a nitrogen flow of 100 $\mathrm{ml} / \mathrm{min}^{-1}$.

\subsection{Extraction of Organochlorine Compounds from Soil Contaminated by Packed Columns}

Packed columns with an internal diameter of $2.5 \mathrm{~cm}$, a length of $10 \mathrm{~cm}$ and a capacity of $120.0 \mathrm{~g}$, of contaminated soil. The gravity leaching process was done using different aqueous media such as: Milli- $\mathrm{Q}$ water, $[\mathrm{NaOH}]=0.001 \mathrm{M},[\mathrm{HCl}]=$ $0.001 \mathrm{M}$. The surfactant solutions were prepared at Critical Micellar Concentration $(\mathrm{CMC})$, using ionic surfactant $[\mathrm{SDS}]=8.1 \times 10^{-3} \mathrm{M}$., nonionic surfactant [Triton X-114] $=3.5 \times 10^{-4} \mathrm{M}$. Also, $1.0 \mathrm{~g}$ of humic acids was diluted in $0.2 \mathrm{M}$ of $\mathrm{NaOH}$ and acetonitrile during 4 days. The leachate solution obtained, after the washing process in each column, was analyzed by gas chromatography-mass spectrometry with electron capture detector (GC-EC-Ms), the most commonly used analytical technique for the determination of organochlorine pesticides and pesticides. In some cases, GC-EC-Ms can be coupled with mass spectrometry. Mass determination is commonly performed for structural confirmation purposes rather than for quantification [18] [25].

\subsection{Extraction and Quantification of Organochlorine Compound}

\subsubsection{Liquid-Liquid Microextraction in Soil Washing Solutions}

The quantification of contaminants in the soil washing solutions was carried out by a liquid-liquid microextraction (LLME). The liquid-liquid microextraction was carried out in a 1:1 ratio with dichloromethane and $2.0 \mathrm{ml}$ of the soil washing solution. The solutions were agitated with an AX681/2 vortex mechanical stirrer for 5 minutes at a speed of $10,000 \mathrm{rpm}$. And subsequently centrifuged at $14,000 \mathrm{rpm}$ for 1 hour to remove the particles in suspension and subsequently 
the samples of the extracts were passed through $0.2 \mu \mathrm{m}$ Iso-Disc ${ }^{\mathrm{TM}}$ Filters N-25-2 Filters Nylon $25 \mathrm{~mm} \times 0.2 \mathrm{~mm}$ of SUPELCO. The extracts from the samples were pre-concentrated in dichloromethane which was then evaporated and the residue was diluted in hexane in order to analyze the compounds of interest by GC-EC-Ms.

\subsubsection{Solid-Liquid Microextraction of Contaminants in Soil}

For quantification of residual pollutants in soil, after the washing process, soil samples were dried at room temperature to avoid the volatilization of contaminants; later on a solid phase microextraction was performed using $1.0 \mathrm{~g}$ of soil that is placed in a glass jar (WHEATON) with a capacity of $20 \mathrm{~mL}$. The extraction is performed with the addition of $3.0 \mathrm{ml}$ of hexane-grade HPLC. The flasks are left in the ultrasound bath for 2 hours in order to get a complete homogenization. After the zoning process, the supernatant is poured into Eppendorf tubes and centrifuged 13,000 rpm for $30 \mathrm{~min}$. The samples are filtered with $0.2 \mu \mathrm{m}$ Iso-Disc ${ }^{\mathrm{TM}}$ Filtres N-25-2 Nylon $25 \mathrm{~mm} \times 0.2 \mu \mathrm{m}$ membranes to separate the suspended particles, and then the filtered sample is placed in $2.0 \mathrm{ml}$ vials to be placed in the auto sampler (Agilent Technologies G2614A) with a 7683B Series Injector.

\subsubsection{Instrument}

GC-MS analysis was performed by an Agilent 6890N gas chromatography (Agilent Technologies, CA, USA) coupled to a MS5975 mass spectrometer and equipped with a split/splitless injector port. Thes amples were separated by a \# AB002 capillary column (5\% phenyl-95\% methyl siloxane, $30 \mathrm{~m} \times 250 \mu \mathrm{m} \times$ $0.25 \mu \mathrm{m}$ ). Helium was used as carrier gas at a constant flow of $2.9 \mathrm{~mL} / \mathrm{min}$; splitless injection; injection temperature was $250^{\circ} \mathrm{C}$; the oven temperature was initially maintained at $70^{\circ} \mathrm{C}$ (held for $1 \mathrm{~min}$ ), then increased to $180^{\circ} \mathrm{C}$ at a rate of $10^{\circ} \mathrm{C} / \mathrm{min}$ (held for $1 \mathrm{~min}$ ), and finally reached $270^{\circ} \mathrm{C}$ at $3^{\circ} \mathrm{C} / \mathrm{min}$ (held for 3 $\mathrm{min})$. The total run time was about $50 \mathrm{~min}$. The GC transfer line was set at $280^{\circ} \mathrm{C}$. The mass spectrometer was maintained in the electron impact (EI) ionization mode with a source temperature of $250^{\circ} \mathrm{C}$. The electron energy was $70 \mathrm{eV}$ and the filament current was $200 \mu \mathrm{A}$. Chromatograms were acquired in "scan" mode scanning the quadrupole from $\mathrm{m} / \mathrm{z} 35$ to $\mathrm{m} / \mathrm{z} 450$.

To confirm the peaks of organochlorine pesticides, it was corroborated by comparing the spectra obtained from the samples with the corresponding standards.

\section{Results}

\subsection{Physicochemical Analysis of Contaminated Soil}

The results of soil physical characterization, by the Bouyoucus and X-Ray Diffraction methods, are reported in Table 1. From these data it can be established that used soil corresponds to a clay-silty soil.

The physical and textural characterization of the contaminated soil exhibit 
Table 1. Physicochemical analysis of contaminated soil.

\begin{tabular}{cc}
\hline Parameter & Value \\
\hline Organic matter (\%) & 0.37 \\
C.E.C $(\mathrm{meq} / \mathrm{100 \textrm {g } )}$ & 102.66 \\
Conductivity $\left(\mathrm{mS} \cdot \mathrm{cm}^{-1}\right)$ & 14.32 \\
Real apparent $\left(\mathrm{g} \cdot \mathrm{cm}^{-3}\right)$ & 2.50 \\
Apparent density $\left(\mathrm{g} \cdot \mathrm{cm}^{-3}\right)$ & 1.64 \\
Porosity $(\%)$ & 34.33 \\
Hygroscopic Water $(\%)$ & 1.34 \\
Humidity at Field Capability $(\%)$ & 5.68 \\
Sand (\%) & 30 \\
Clay (\%) & 49 \\
\hline
\end{tabular}

${ }^{a}$ Cationic exchange capacity.

low permeability $\left(2.7 \times 10^{-6}\right)$,with acidic $\mathrm{pH}$ of 5.5 values and sandy loam properties due to its content of sand, clay and silt.

\subsection{X-Ray Diffraction Analysis of Soil}

In Figure 1, it is shown the diffractogram of the contaminated soil sample, with identification of signals corresponding to the different mineralogical phases, as follows: the most intense signal corresponds to the quartz $\left(\mathrm{SiO}_{2}\right)$ of which $64 \%$ is present, followed by $\mathrm{Al}_{2} \mathrm{O}_{3}$ with $14 \%$ and in a lower order of abundance is Ortoclase $\left(\mathrm{KAlSi}_{3} \mathrm{O}_{8}\right)$ followed by Albite $\left(\mathrm{NaAlSi}_{3} \mathrm{O}_{8}\right)$, as well as potassium feldspars.

Major intensity signal corresponds to quartz $\left(\mathrm{SiO}_{2}\right)$ which is the most abundant mineral specie found in agricultural soil; also, there are characteristic signals for two clay species kaolinite $\left(\mathrm{KAl}_{3} \mathrm{SiO}_{8}\right)$ and albite $\left(\mathrm{KAl}_{3} \mathrm{SiO}_{8}\right)$.

\subsection{Thermogravimetric Analysis of Contaminated Soil}

In Figure 2, it is presented the thermograms corresponding to the initial sample of contaminated soil. It is observed that at a temperature of $120^{\circ} \mathrm{C}$ the signal corresponding to the organic compounds and at $600^{\circ} \mathrm{C}$ the signal corresponding to the loss of water.

\subsection{Qualitative and Quantitative Analysis of Soil Contaminants}

In order to assess the precision of organochlorine compounds detection by GC-Ms technique, it was necessary to get the calibration curve, then a set of organochlorine compounds solutions, from $0.01 \mu \mathrm{g} / \mathrm{L}$ to $0.04 \mu \mathrm{g} / \mathrm{L}$, was prepared using hexane HPLC grade as a solvent. In this concentration range it was possible to get a 0.999 correlation coefficient for organochlorine compounds detection.

For the analysis of the total concentration of pollutants in the agricultural soil, a solid-liquid extraction was carried out with the methodology described. 


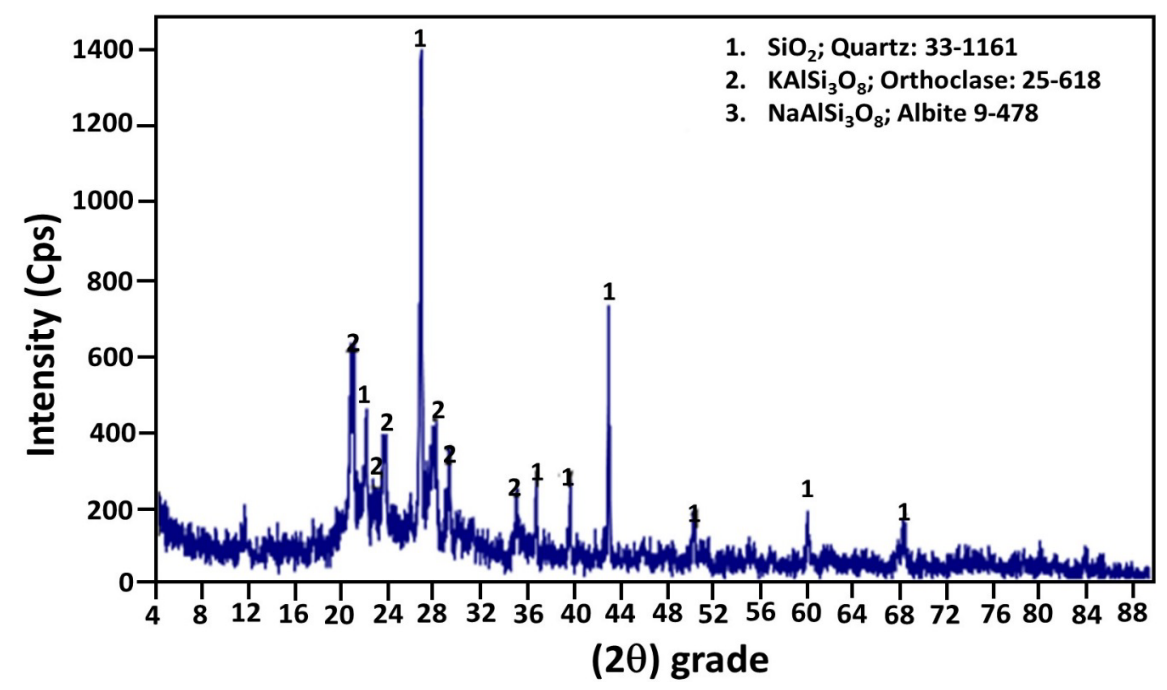

Figure 1. Diffractogram of the contaminated soil sample. $\lambda=1.5418 \AA$, Voltage $30 \mathrm{KV}$, $20 \mathrm{~mA}$ and sweep speed of $2^{\circ}$ per minute.

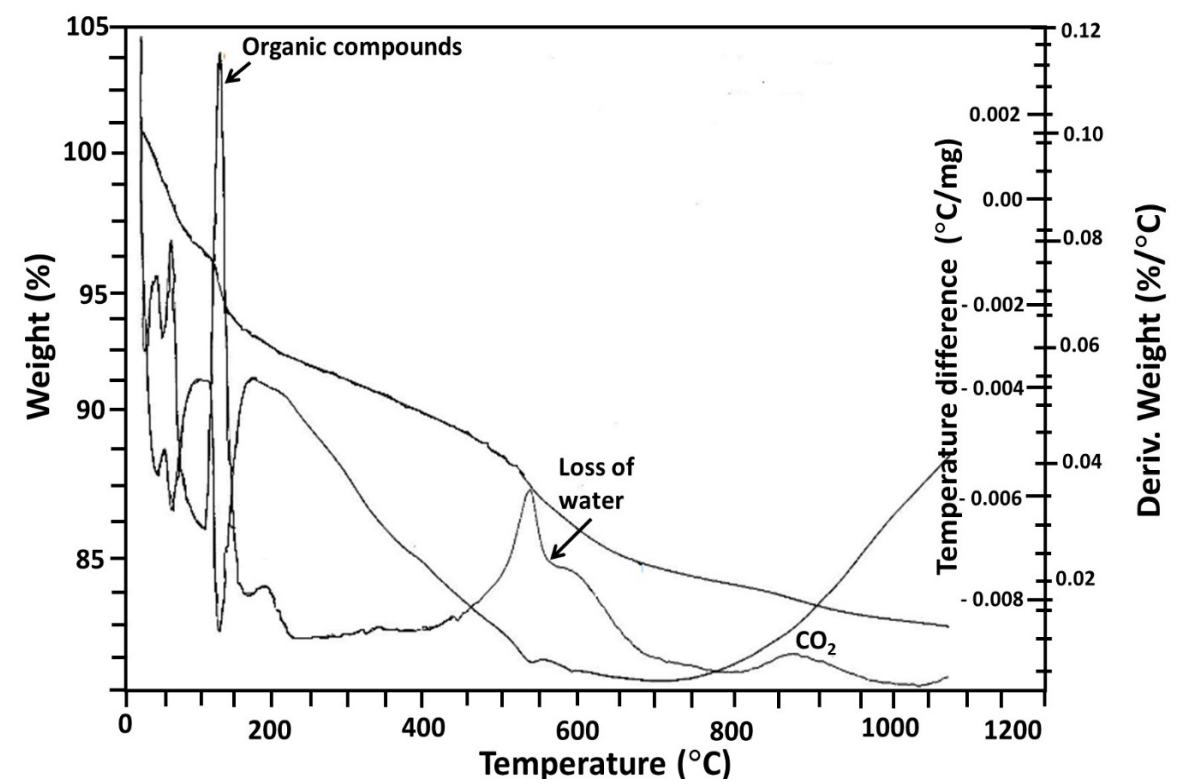

Figure 2. Thermogram analysis of contaminated soil. Temperature range $0^{\circ} \mathrm{C}$ to $1200^{\circ} \mathrm{C}$, Heating rate of 5 degrees/min and nitrogen flow of $100 \mathrm{ml} / \mathrm{min}$.

In Figure 3, the chromatogram of the qualitative analysis of soil contaminants is shown. It is observed the presence of organochlorine compounds such as $p$, $p^{\prime}$-DDT which has the highest peak intensity at a time of 45.2 minutes, with a concentration of $2590 \mathrm{mg} / \mathrm{kg}$. Degradation products such as $p, p^{\prime}$-DDE are present at a time of 41.1 minutes, having a concentration of $1510 \mathrm{mg} / \mathrm{kg}$, and the $p, p^{\prime}$-DDD at a time of 43.5 minutes with a concentration of $1006 \mathrm{mg} / \mathrm{Kg}$, in a lower concentration aldrin and dieldrin were detected at a time of 35.0 minutes and 42.1 minutes, with a concentration of $121.0 \mathrm{mg} / \mathrm{kg}$ and $100 \mathrm{mg} / \mathrm{kg}$, respectively. However, it is important to note that these organochlorine compounds are found at high organochlorine concentrations. 


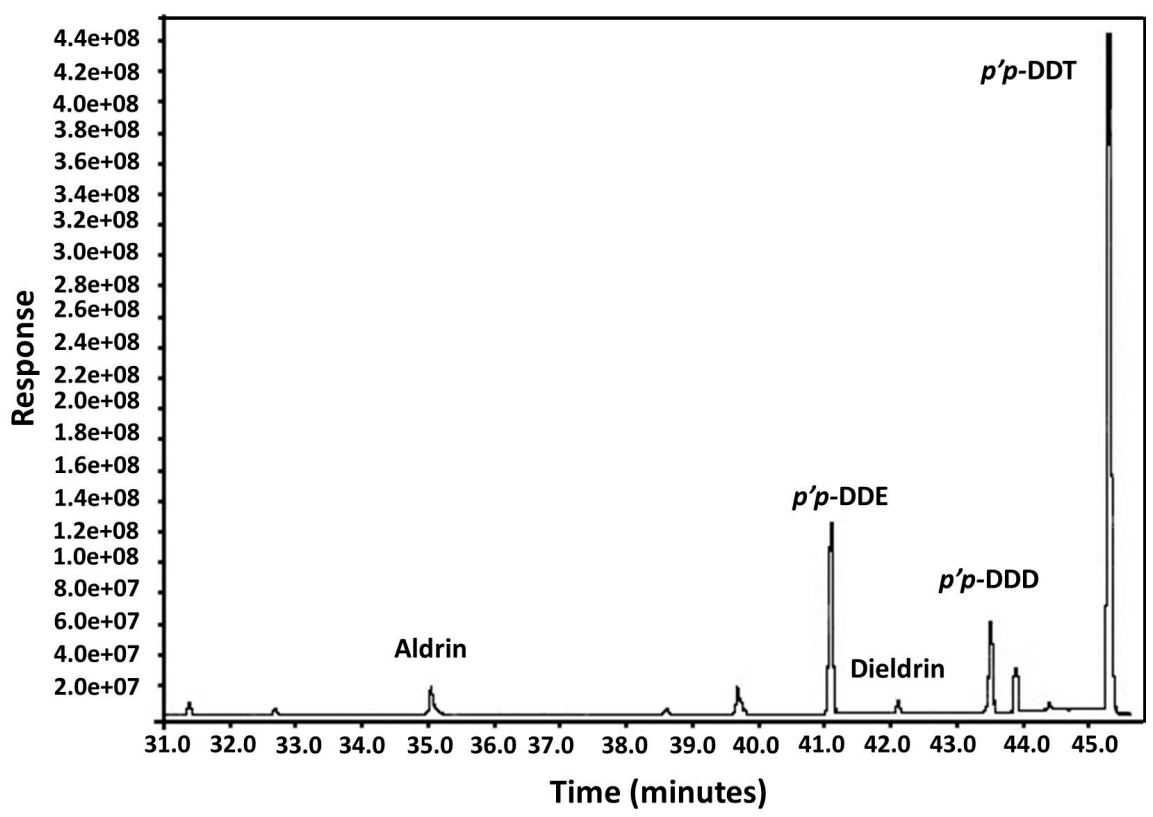

Figure 3. Chromatogram of the initial soil extract. Temperature $250^{\circ} \mathrm{C}$, time $50 \mathrm{~min}$. Helium, with flow of $2.9 \mathrm{ml} / \mathrm{min} ; 1.0 \mu \mathrm{l}$ of the extract was injected in splitless mode. Invetory Column \# AB002 $30.0 \mathrm{~m} \times 250 \mu \mathrm{m} \times 0.25 \mu \mathrm{m}$ Calibrated.

\subsection{Washing and Extraction of Organochlorine Compounds with Different Aqueous Medium}

The organochlorine compounds can interact with soil solids by a series of mechanisms that can mainly be by hydrophobic interaction, ligand exchange, hydrogen bonding and ion exchange. The adsorption on the soil of the non-ionizable organic compounds tends to increase with the lipophobicity of the compound; the adsorption of these products is strongly related to the organic matter content of the soil, as well as to the type of clay phyllosilicates and oxides of Iron and aluminum [26].

In Table 2(a) and Table 2(b), percentages of extracted pesticides (pesticide desorption) are reported for each of the columns, in reference to the different solutions used. It is important to point out that there are significant differences in some of the extraction media for different pesticides.

This is due to the hydrophobicity of the extraction media. As a result, a higher percentage of acetonitrile extraction in each of the organochlorine compounds as $p, p^{\prime}-\mathrm{DDT}$ (91\%), $p, p^{\prime}$-DDE (92\%), $p, p^{\prime}$-DDD (96\%), aldrin (98.6\%) and dieldrin (98\%). However the acetonitrile is discarded as an extraction medium, because it is a carcinogenic organic compound.

The use of surfactants like SDS and Triton X-114 in the removal of hydrophobic organic compounds in various environmental matrices have been successfully performed, are environmentally friendly and have been used in recent biodegradation and removal studies of persistent organic pollutants [17].

In Table 2(b) can be observed that the highest desorption of pollutants by using acetonitrile is for $p, p^{\prime}$-DDT 90.1\%; $p, p^{\prime}$-DDE 92.0\%; $p, p^{\prime}$-DDD 96.0\%; 
Table 2. (a) Pesticides extracted by different solutions, using ANOVA through the JUMP program for statistical data. (b) Pesticides extracted by different solutions, using ANOVA through the JUMP program for statistical data.

(a)

\begin{tabular}{ccccc}
\hline \multirow{2}{*}{ Pesticides } & \multicolumn{4}{c}{ Percentages of Pesticide Extraction in Soils by Different Solutions } \\
\cline { 2 - 5 } & $\mathrm{H}_{2} \mathrm{O}$ Milli-Q & {$[\mathrm{NaOH}]=0.001 \mathrm{M}$} & {$[\mathrm{NaOH}]=0.1 \mathrm{M}$} & {$[\mathrm{HCl}]=0.001 \mathrm{M}$} \\
\hline$p, p^{\prime}$-DDT & $14.0 \pm 1.5 \mathrm{~g}$ & $19.0 \pm 0.6 \mathrm{f}$ & $20.0 \pm 1.0 \mathrm{f}$ & $21.0 \pm 0.6 \mathrm{e}$ \\
$p, p^{\prime}$-DDE & $15.0 \pm 0.6 \mathrm{~g}$ & $20.0 \pm 0.6 \mathrm{f}$ & $21.0 \pm 3.0 \mathrm{f}$ & $23.0 \pm 0.6 \mathrm{e}$ \\
$p, p^{\prime}$-DDD & $18.0 \pm 1.0 \mathrm{~g}$ & $22.0 \pm 0.6 \mathrm{f}$ & $23.0 \pm 0.6 \mathrm{f}$ & $28.0 \pm 0.6 \mathrm{e}$ \\
Dieldrin & $13.0 \pm 0.3 \mathrm{~g}$ & $24.0 \pm 0.3 \mathrm{f}$ & $23.0 \pm 0.1 \mathrm{f}$ & $33.0 \pm 0.6 \mathrm{e}$ \\
Aldrin & $12.0 \pm 0.4 \mathrm{~g}$ & $18.0 \pm 0.2 \mathrm{f}$ & $18.0 \pm 0.1 \mathrm{f}$ & $29.0 \pm 0.1 \mathrm{e}$ \\
\hline
\end{tabular}

The different letters indicate significant differences in the extraction of pesticides in the different media with $\alpha<0.05$.

(b)

\begin{tabular}{ccccc}
\hline \multirow{2}{*}{ Pesticides } & \multicolumn{4}{c}{ Percentages of Pesticide Extraction in Soils by Different Solutions } \\
\cline { 2 - 5 } & $\begin{array}{c}\text { SDS } \\
{\left[8.1 \times 10^{-3} \mathrm{M}\right]}\end{array}$ & $\begin{array}{c}\text { Triton X-114 } \\
{\left[3.5 \times 10^{-4} \mathrm{M}\right]}\end{array}$ & Humic Acid & Acetonitrile \\
\hline$p, p^{\prime}$-DDT & $39.0 \pm 2.0 \mathrm{c}$ & $63.0 \pm 0.6 \mathrm{~b}$ & $37.0 \pm 1.0 \mathrm{~d}$ & $91.0 \pm 1.0 \mathrm{a}$ \\
$p, p^{\prime}$-DDE & $40.0 \pm 0.6 \mathrm{c}$ & $64.0 \pm 1.5 \mathrm{~b}$ & $35.0 \pm 0.6 \mathrm{~d}$ & $92.0 \pm 1.0 \mathrm{a}$ \\
$p, p^{\prime}$-DDD & $42.0 \pm 0.6 \mathrm{c}$ & $65.0 \pm 0.6 \mathrm{~b}$ & $38.0 \pm 0.6 \mathrm{~d}$ & $96.0 \pm 1.5 \mathrm{a}$ \\
Dieldrin & $47.0 \pm 0.3 \mathrm{c}$ & $67.0 \pm 0.6 \mathrm{~b}$ & $37.0 \pm 0.2 \mathrm{~d}$ & $98.0 \pm 0.3 \mathrm{a}$ \\
Aldrin & $45.0 \pm 0.5 \mathrm{c}$ & $72.0 \pm 0.3 \mathrm{~b}$ & $36.0 \pm 0.6 \mathrm{~d}$ & $98.6 \pm 0.8 \mathrm{a}$ \\
\hline
\end{tabular}

The different letters indicate significant differences in the extraction of pesticides in the different media with $\alpha<0.05$.

dieldrin $98.0 \%$ and aldrin $100 \%$. With respect to the use of surfactants and humic acid, the order of desorption of each of the organic pollutants is Triton $\mathrm{X}-114>$ SDS $>$ humic acid. The use of acetonitrile in this desorption process was only as a comparative medium and the use of surfactants to anionic critical micellar concentration (triton X-114), ionic surfactant SDS and the use of humic acids to be able to have in the soil a greater of hydrophobic groups that allow us to have a greater desorption of the pollutants.

The lowest percentages of extraction were obtained with water due to the polarity of the molecule. One of the main advantages of this experimental approach is that samples are prepared and analyzed in a simpler way, since it is not required special conditions for extraction, cleaning or additional treatments in order to determine the organochloride pesticides in agriculture soil which it can be a good option for extracting organic compounds in environmental matrices.

\section{Conclusions}

The SPME coupled with GC/MS has been demonstrated to be a simple, rapid, solvent free and sensitive method for the determination of organochlorine compounds in extracts soils. In this work, the analyzed soil has high concentrations of organochlorine compounds. From the study of leaching of pesticides by 
different means, it is concluded that there is a greater extraction of organochlorines in the following order: Acetonitrile $>$ Triton-X114 $>$ DSD $>$ Acid humic $>$ $\mathrm{HCl}>\mathrm{NaOH}>\mathrm{H}_{2} \mathrm{O}$-Milli Q. The optimized method exhibited wide linearity, low detection limits and good repeatability. Moreover, good relative recoveries were obtained when method was used for the analysis of OCPs in soil samples, which illustrated the feasibility of the proposed SPME-GC/MS.

\section{Acknowledgements}

Author Lluvia P. Medina Armenta is very thankful to CONACyT in México, for sponsoring the doctoral fellowship under which this work has been. Also thanks to Professor Ma. Guadalupe García Jiménez for the contribution with the instrumental analysis of Gas Chromatography.

\section{References}

[1] Ortiz, I., Avila-Chávez, M.A. and Torres, L.G. (2013) Plaguicidas en México: usos, riesgos y marco regulatorio. Revista Latinoamericana de Biotecnología Ambiental y Algal, 4, 26-46. https://doi.org/10.7603/s40682-013-0003-1

[2] CICOPLAFEST, Comisión Intersecretarial Para el Control del Proceso y uso de Plaguicidas, Fertilizantes y Sustancias Toxicas. (2016). Catálogo de Plaguicidas.

http://www.cofepris.gob.mx/AZ/Paginas/Plaguicidas\%20y\%20Fertilizantes/Catalog oPlaguicidas.aspx

[3] Fernando, P.C. (2017) Pesticides, Environment, and Food Safety. Food and Energy Security, 6, 48-60. https://doi.org/10.1002/fes3.108

[4] Koblizkova, M., Ruzickova, P., Cupr, P., Komprda, J., Holoubek, I. and Klanova, J. (2009) Soil Burdens of Persistent Organic Pollutants: Their Levels, Fate, and Risks. Part IV. Quantification of Volatilization Fluxes of Organochlorine Pesticides and Polychlorinated Biphenyls from Contaminated Soil Surfaces. Environmental Science Technology, 43, 3588-3595.

https://www.ncbi.nlm.nih.gov/pubmed/19544859

https://doi.org/10.1021/es9003944

[5] Valerón, P.F., Pestano, J.J., Luzardo, O.P., Zumbado, M.L., Almeida, M. and Boada, L.D. (2009) Differential Affects Exerted on Human Mammary Epithelial Cells by Environmentally Relevant Organochlorine Pesticides Either Individually or in Combination. Chemico Biological Interactions, 180, 485-491. https://doi.org/10.1016/j.cbi.2009.04.010

[6] Shen, Y., Zhao, S., Li, Y., Liu, Q., Ma., Ch., Mao, H., Liao, Y. and Jun, M. (2017) A Feasible Approach to Dispose of Soil Washing Wastes: Adsorptive Removal of Chlorobenzene Compounds in Aqueous Solutions Using Humic Acid Modified with Monoolein (HA-M). Royal Society Chemistry, 7, 9662-9668. https://doi.org/10.1039/C6RA17949E

[7] Karnchanasest, B. and Hawker, D.W. (2011) A Column Test for Leaching of Organochlorines from Soil by Amphiphilic Nonionic Nanopolymers. Journal of Environmental Science and Health Part B, 46, 411-418. https://doi.org/10.1080/03601234.2011.572508

[8] Gao, J.P., Maguhn, J., Spitzauer, P. and Kettrup, A. (1998) Sorption of Pesticides in the Sediment of the Teufelsweiher Pond (Southern Germany). II: Competitive Adsorption, Desorption of Aged Residues and Effect of Dissolved Organic Carbon. 
Water Research, 32, 2089-2094. https://doi.org/10.1016/S0043-1354(98)00140-7

[9] Ding, G., Novak, J.M., Herbert, S. and Xing, B. (2002) Long-Term Tillage Effects on Soil Metolachlor Sorption and Desorption Behavior. Chemosphere, 48, 897-904. http://sci-hub.cc/10.1016/s0045-6535(02)00188-1 https://doi.org/10.1016/S0045-6535(02)00188-1

[10] Chu, W. and Kwan, C.Y. (2003) Remediation of Contaminated Soil by a Solvent/Surfactant System. Chemosphere, 53, 9-15.

[11] Abdul, A.S. and Gibson, T.L. (1991) Laboratory Studies of Surfactant Enhanced Washing of Polychlorinated Biphenyl from Sandy Material. Environmental Science and Technology, 25, 665-671. https://doi.org/10.1021/es00016a009

[12] Paradelo, R., Conde-Cid, M., Arias-Estevez, M., Novoa Muñoz, J.C., Alvarez-Rodríguez, E., Fernandez-Sanjurjo, M.J. and Núñez-Delgado, A. (2017) Removal of Anionic Pollutants by Pine Bark Is Influenced by the Mechanism of Retention. Chemosphere, 167, 139-145.

[13] Mao, Y., Sun, M., Yang, X., Wei, H., Song, Y. and Xin, J. (2013) Remediation of Organochlorine Pesticides (OCPs) Contaminated Soil by Successive Hydroxypropyl- $\beta$-Cyclodextrin and Peanut Oil Enhanced Soil Washing-Nutrient Addition: A Laboratory Evaluation. Journal Soils Sediments, 13, 403-412. https://doi.org/10.1007/s11368-012-0628-4

[14] Brusseau, M.L., Jessup, R.E., Rao and Jessup, P.S.C. (1991) Nonequilibrium Sorption of Organic Chemicals: Elucidation of Rate-Limiting Processes. Environmental Science Technology, 25, 134-142. https://doi.org/10.1021/es00013a015

[15] Gebremariam, S.Y., Beutel, M.W., Flury, M., Harsh, J.B. and Yonge, D.R. (2012) Nonsingular Adsorption/Desorption of Chlorpyrifos in Soils and Sediments: Experimental Results and Modeling. Environmental Science Technology, 46, 869-875. https://doi.org/10.1021/es203341b

[16] Rios, L.E., David, M., Vazquez-Arenas, J. and Anderson, W.A. (2012) Use of Surfactants and Blends to Remove DDT from Contaminated Soils. The Canadian Journal of Chemical Engineering, 9999, 1-7. https://doi.org/10.1002/cjce.21620

[17] Feria-Reyes, R., Medina-Armenta, P., Teutli-Leon, M., García-Jiménez, M.G. and Gonzalez, I. (2011) A New Approach for Atrazine Desorption, Extraction and Detection from a Clay-Silty Soil Sample. American Journal of Analytical Chemistry, 2, 64-68. https://doi.org/10.4236/ajac.2011.228125

[18] Cai, J., Zhu, F., Ruan, W., Liu, L., Lai, R., Zeng, F. and Ouyang, G. (2013) Determination of Organochlorine Pesticides in Textiles using Solid-Phase Microextraction with Gas Chromatography-Mass Spectrometry. Microchemical Journal, 110, 280-284.

[19] Salem, N.M., Ahmad, R. and Estaitieh, H. (2009) Organochlorine Pesticide Residues in Dairy Products in Jordan. Chemosphere, 77, 673-678.

[20] Erger, C., Balsaa, P., Werres, F. and Schmidt, T.C. (2012) Multi-Component Trace Analysis of Organic Xenobiotics in Surface Water Containing Suspended Particular Matter by Solid Phase Extraction/Gas Chromatography-Mass Spectrometry. Journal Chromatographyc A, 1249, 181-189.

[21] Souza-Silva, E.A. and Pawliszyn, J. (2017) Chapter Sixteen-Recent Advances in Solid-Phase Microextraction for Contaminant Analysis in Food Matrices. Comprehensive Analytical Chemistry, 76, 483-517.

[22] Al-Alam, J., Ziad, F., Chbani, A. and Millet, M. (2017) A Multiresidue Method for the Analysis of 90 Pesticides, 16 PAHs, and 22 PCBs in Honey using QuECh- 
ERS-SPME. Analytical and Bioanalytical Chemistry, 409, 5157-5169.

https://link.springer.com/article/10.1007/s00216-017-0463-y https://doi.org/10.1007/s00216-017-0463-y

[23] Ouyang, G., Vuckovic, D. and Pawliszyn, J. (2011) Nondestructive Sampling of Living Systems using in Vivo Solid-Phase Microextraction. Chemical Review, 111, 2784-2814. https://doi.org/10.1021/cr100203t

[24] Bai, Z.W., Pilote, A., Sarker, P.K., Vandenberg, G. and Pawliszyn, J. (2013) In Vivo Solid-Phase Microextraction with in Vitro Calibration: Determination of Off-Flavor Components in Live Fish. Analytical Chemistry, 85, 2328-2332. https://doi.org/10.1021/ac3033245

[25] Li, J.L. and Chen, B.H. (2002) Solubilization of Model Polycyclic Aromatic Hydrocarbons by Nonionic Surfactants. Journal Chemical Engineering Science, 57, 2825-2835.

[26] Lindstrom, J.E. and Braddock, J.F. (2002) Biodegradation of Petroleum Hidrocarbons at Low Temperature in the Presence of the Dispersant Corexit 9500. Journal Marine Pollution Bulletin, 44, 739-747. 